
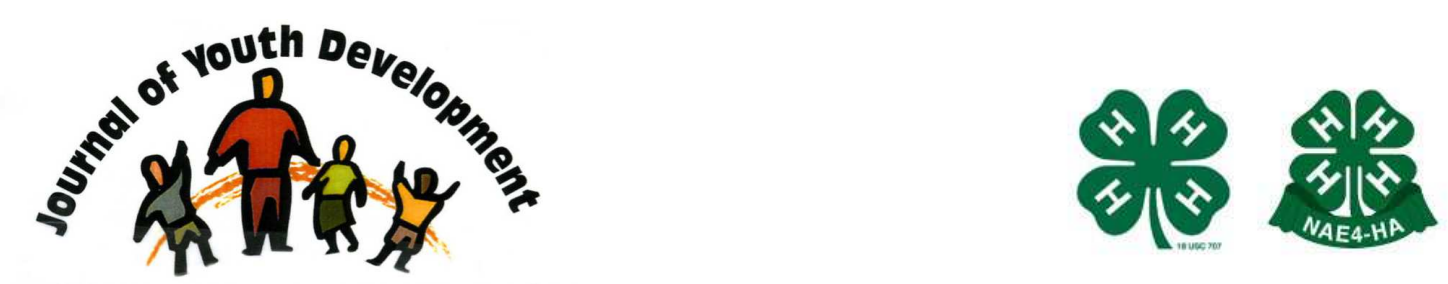

Bridging Research \& Practice

\title{
A Person-Centered, Asset-Based Community Development Framework for Youth with Special Health Care Needs/Disabilities in Transition to Adulthood
}

\author{
Heather H. Boyd \\ Virginia Tech \\ Blacksburg, VA \\ hboyd@vt.edu \\ Beth Swedeen \\ Waisman Center's University Center for Excellence in \\ Development Disabilities at UW-Madison \\ Madison, Wisconsin \\ swedeen@waisman.wisc.edu
}




\title{
JOURNAL OF YOUTH DEVELOPMENT \\ bridging research and practice

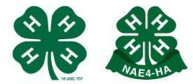

Bridging Research \& Practice

Volume 2, Number 1, Summer 2007

Article 0701PA003

\section{A Person-Centered, Asset-Based Community Development Framework for Youth with Special Health Care Needs/Disabilities in Transition to Adulthood}

\author{
Heather H. Boyd \\ $\mathrm{Ag}$ and Extension Education, Virginia Tech \\ Beth Swedeen \\ Waisman Center's University Center for Excellence in \\ Development Disabilities at UW-Madison
}

\begin{abstract}
In the United States, 12.8 percent of children under 18 have special health care needs. Ninety percent of youth in America with special health care needs and/or disabilities can now be expected to reach adulthood. Youth with special health care needs and/or disabilities are less likely to experience successful transition to adulthood in comparison to youth without special health care needs. This article presents a person-centered, asset-based community development approach that assisted youth in achieving transition and inclusion-oriented outcomes. Examples are drawn from a Healthy \& Ready to Work demonstration project in Wisconsin. At the center of our approach to transition were community connectors -- adults who knew the personal interests and assets of youth and who found opportunities in the community that matched individual youth interests. Implications for youth development professionals as successful community connectors are described.
\end{abstract}

\section{Who are youth with special health care needs and/or disabilities?}

In the United States, 12.8 percent of children under 18 - or 9.4 million -- have special health care needs (U.S. DHHS, 2004). Children with special health care needs are defined by the U.S. Maternal and Child Health Bureau as "those who have or are at increased risk for a chronic physical, developmental, behavioral or emotional condition and who also require health and related services of a type or amount beyond that required by children generally" (McPherson et al, 1998). 
For youth development professionals who may not work regularly with youth with special health care needs and/or disabilities, this article and the work of this project focuses on the individual and unique needs and interests of each youth. In the field of disabilities, this is referred to as a person-centered approach. In this article we describe youth who have given us permission to share information about them. This includes one young woman, who has a metabolic disorder that affects her joints, also uses a wheelchair. She has good interpersonal skills and would like to be a doctor someday. Another youth has Down syndrome; he would like a career in child care and often cares for his nieces and nephews. For additional descriptions of youth, see http://www.waisman.wisc.edu/cedd/WRC/Txt/transitionstories.html (Swedeen, 2003).

\section{What transition outcomes have youth with special health care needs and/or disabilities experienced?}

Perceptions of successful transition are often defined culturally, thus describing transition passages across cultures and expectations can be fraught with difficulty (Hogan \& Astone, 1986). Regardless, many youth development practitioners in the United States consider transition to adulthood to be characterized by a combination of some of the following accomplishments, or completion of stages:

- completion of formalized schooling,

- entry and/or advancement in the paid labor force,

- establishment of mature, adult relationships (which may involve partnership, marriage and sometimes parenthood) (Hogan \& Astone, 1986).

Ninety percent of youth in America with special health care needs and/or disabilities can now be expected to reach adulthood (White \& Gallay, 2005). All markers of transition can apply to the lives of youth with special health care needs and/or disabilities, depending on the young person's goals, assets and access to opportunities. Other markers of success for youth with special health care needs and/or disabilities may be: involvement in civic life through volunteer work, participation in community organizations and activities and independent living.

The reality for many youth with special health care needs and/or disabilities, their families and their communities is that they are less likely to experience successful transition to adulthood than youth without special health care needs and/or disabilities. Youth with special health care needs and/or disabilities are less likely to graduate from high school, find employment or pursue secondary education (Blum, R., White, P. \& Gallay, L., 2005).

\section{What frameworks for transition to adulthood exist for these youth?}

Education and health care systems offer frameworks for youth transition to adulthood for youth with special health care needs and/or disabilities. However, these frameworks seldom extend beyond the parameters of specific agencies. For example, educational frameworks focus almost exclusively on academic goals that can be accomplished in school settings with teaching staff. In reality, multiple systems, both formal and informal, are necessary for youth to participate in community life and explore future goals.

Within special education systems, transition to adult life has many meanings and considerations for youth with special needs and these can range from developmental processes to legislative mandates (Hanley-Maxwell, 1999). For example, as a result of the Individuals with Disabilities 
Education Act (IDEA), transition issues are to be considered in each youth's Individualized Education Plan (IEP).

Many youth development professionals may be familiar with IEPs because youth with special needs and their families and/or school-based team create these plans to help the youth reach specific goals during the school year. Creating an IEP can involve a collaborative team planning processes with youth and can include both paid professionals, family members and unpaid but interested friends and acquaintances. Youth development professionals are naturals to be invited to these planning sessions, especially when they have a personal and/or professional connection to youth with special needs.

Once a youth is 16 (age 14 in Wisconsin), federal law mandates that transition planning be a part of each youth's IEP in the form of a statement of transition service needs. At 16, a youth's IEP is to include a statement of needed transition services, including interagency responsibilities or needed linkages. Frameworks for transition in education extend beyond those mentioned briefly here.

In health care, a recent review of literature about transition to adulthood for adolescents with special health care needs (Betz, 2004) reviewed 43 journal articles from pediatric, nursing, social work, public health, education, disabilities, occupational therapy, and speech/language literature from 1982 through August 2003. Of the 43 articles, two used theoretical frameworks (Bent et al., 2002; Russell, Reinbold \& Maltby, 1996). Both frameworks are team-based models that are situated within health care systems.

Education and health care systems recognize the importance of youth interests, family involvement and community connection for the potential success of youth in transition to adulthood. For example, the Medical Home initiative of the American Academy of Pediatrics, American Academy of Family Physicians, and the federal Bureau of Maternal and Child Health recognize the value of gaining access to community supports outside of health care systems. These agencies encourage a child's primary health care professional to help the youth and family gain access to and coordinate health care, educational services, and other public and private community services that are important to the overall health of the youth and family.

Using team-based education planning and medical home models as part of a community-based transition approach may extend links from formalized systems to communities. Below we describe a transition framework for youth who desire full inclusion into community living as they experience adulthood. The framework is based both on person-centered planning and assetbased community development.

\section{How does a person-centered, asset-based community development approach differ from other frameworks?}

Using a person-centered planning and asset mapping as a community development strategy has the ability to connect youth with formal systems and mandated services, but success is not dependent on service systems alone. This approach can tap into the interests of the youth as well as youth's support network, regardless of formal roles in service systems or structures. It can use, but can also transcend service agreements. 
Person-centered planning is a broad term that encompasses different techniques of futures planning that focuses on individual people and their skills, abilities and goals. Depending on the format used, an IEP meeting can be an example of part of a person-centered planning process.

An asset-based community development approach has been used in a wide variety of situations including public safety, public health and education. For youth with health issues, asset-based community development has been used to promote connection between pediatricians and local associations (McKnight \& Pandack, 1996). Specific to people with disabilities, asset-based community development was used to help strengthen a community in Chicago by integrating adults with developmental disabilities into a neighborhood (O'Connell, 1990).

There are five basic steps to this approach regarding working with people with disabilities (Kretzmann \& McKnight, 1993):

1) map community assets to discover potential partners for people with disabilities,

2) build productive relationships between people with disabilities and the community,

3) mobilize for your purpose and information sharing,

4) convene the community to develop a vision and a plan for the individual and the community,

5) leverage outside resources to support your local purpose.

When applied to youth with special health care needs in transition, person-centered, assetbased community development is based on two central tenets:

- Young people with special health care needs thrive when their gifts and passions are recognized, supported and used in communities.

- Communities thrive when all of their resources and assets are connected and utilized.

\section{How can a person-centered, asset-based community development approach work to link personal interests and assets with community opportunities?}

Blending person-centered planning with asset-based community development helped the Wisconsin Healthy \& Ready to Work demonstration project connect youth with community opportunities. The combination of the information learned during person-centered planning sessions as well as the involvement of people who were invested in building relationships between youth and community partners were both critical to developing experiences that contributed to youth outcomes.

Interpersonally talented and local-network-rich individuals called "community connectors" were recruited to work with individual youth in transition and their family members, friends and other members of their communities. Community connectors facilitated many parts of a youth's transition process, including:

1) asking the youth what they wanted for themselves,

2) probing the youth and those in their circle of support about the youth's assets and

3) making connections in and to the broader community for outlets for youth assets and ways to help the youth achieve their goals and dreams.

The project required the work of these community connectors to deepen the focus on youth connection to six spheres that construct "community" according to the approach:

- individuals,

- associations and groups, 
- institutions,

- economic assets,

- physical assets

- stories.

Community connectors were passionate about working with youth and finding ways to help youth fulfill their dreams and showed tenacity in helping youth to facilitate their own transition processes.

Here is an example of how one youth's passions and assets were linked to community opportunities through a multi-year transition process. Andy has given permission for us to share his story (see http://www.waisman.wisc.edu/cedd/WRC/Txt/transitionstories.html).

Andy received the diagnosis of autism as a teenager after having struggled through diagnoses of emotional and behavioral disorders in middle school. A collaborative team gathered to be part of a person-centered planning process, which was facilitated by his informal community connector, the director of the regional children with special health care needs center. The community connector kept this question in mind as she thought of potential key players: "Who else could be part of Andy's life?" and encouraged Andy and his family to invite these people to his meeting.

During the meeting, the group listened to Andy's dreams, took stock with him regarding his assets and helped him to think about what small piece of his dream he wanted to work on first. While the planning meeting was a one-time event, the assembled team was able to understand Andy's goals and how he might be able to achieve them. Over time and throughout events in Andy's life, including personal discussions and trial-and-error attempts at community connection, Andy and his team learned ways that Andy could successfully connect his interests and assets to community opportunities.

For example, Andy is someone who likes quiet spaces and little noise where he lives and works. Minimizing noise is important to Andy's happiness and ability to function well. He had experienced employment at a sheltered workshop but the long hours and stress created more anxiety for him. He saw an ad for work in a nursing home and applied for a part-time job with the home. He now works there one to three days a week, no more than four hours at a time. His community connector and his case worker helped him develop a budget so that he could pay all of his bills, work part-time and still receive some support from Social Security.

Andy also volunteers part-time at the nursing home, and used his own money to have his two dogs trained to be therapy dogs for the enjoyment of the residents of the nursing home. At the nursing home, he enjoys conversations with others at a pace that suits him. This schedule allows him to have time for other interests like taking his grandfather to church and babysitting his nephew.

During transition, Andy benefits by having a collaborative team that cares about his interests and abilities. He connects with others in the wider community through the nursing home and its residents. Nursing home residents benefit by experiencing the company of someone who chooses to spend time in conversation with them. The benefits of finding a good fit for a youth person with special needs extends past the individual person and his or her family into the wider community. 


\section{What transition and inclusion outcomes did youth involved in Wisconsin's Healthy \& Ready to Work project experience?}

Examples of transition outcomes for youth associated with the work of two community connectors and their teams appear below. We provide detailed information on implementation strategies to accomplish transition and inclusion-oriented outcomes.

\section{Case one: Rural Wisconsin}

In one Wisconsin community, seven youth and their families chose to participate in transition planning processes using the person-centered, asset-based community development approach. Their community connector was a parent of a transition-aged child with a disability. She also had professional experience with education and health care systems. Six of the seven families had known the community connector before the project. Each youth was between the ages of 15 and 25 and all had cognitive disabilities. Some had other diagnoses as well, which were conditions that required medication.

After acquainting youth and their families with steps in the person-centered planning process, this community connector hosted and facilitated collaborative planning team sessions where each youth and 4-10 team members attended. Team members included parents, siblings, teachers, family friends and providers of other services. Over the next six months, the connector mapped different community opportunities to youth goals, made introductions between youth and community contacts and followed up to see how things went. After six months, the teams gathered to share successes and to formulate future steps. The teams decided that they wanted to continue to meet at least twice a year to maintain energy and commitment and to learn from each other, even if the community connector could not participate in the group meetings.

Examples of positive transition and inclusion-oriented outcomes for these youth and their collaborative teams included:

- employment at a grocery store for one youth,

- volunteering at the humane society for another youth,

- serving as an usher in his faith community for a third youth,

- creating and using a personal exercise plan for strengthening by and for a fourth youth,

- meal planning, preparation and sharing for another youth and one of his team members,

- opening their first checking and savings accounts for several youth, along with learning budgeting and money management.

We don't know if any of these outcomes would have occurred without the person-centered, asset-based approach, but we do know that lives of these youth have expanded and broadened because of the work that they, their teams and their community connector committed to. "Person-centered planning brought me out of my cave and opened my mind to new possibilities for my son," one parent told us. Another parent said, "We parents have to overcome the perceived risks of letting our children be part of the community. We are so worried about failure or rejection, but there are no benefits without risks." One youth asked, "When are we going to have our next meeting?"

\section{Case two: Urban Wisconsin}

In another Wisconsin community, the community connector worked with six youth, all between the ages of 14 and 21 . The community connector was in the education profession, bilingual and knew personally many Spanish-speaking members of the neighborhood. Each of the youth 
had mental health issues and/or other major health concerns. Some of the youth were undocumented immigrants and not eligible for county, state or federal services. All participating youth were connected to the project because the community connector was their public school teacher. Participation was initiated through the community connector rather than by the youth or family.

The community connector used a person-centered planning tool with each youth a few weeks before the school-based and family teams met with the youth to create their IEPs. Interests, skills and opportunities were then incorporated into the plan for the coming year. The community connector/teacher and other school staff then connected youth with opportunities as discussed in the planning process.

Transition- and inclusion-related outcomes for youth in this community included:

- becoming a hospital volunteer for one youth and volunteering at a nationally-affiliated community organization for other youth;

- applying for and using a library card for all youth;

- learning how to open a bank account for other youth; and

- learning how to negotiate prices at local shops where that is the custom.

In this community, youth built stronger relationships with adults at school, with local library staff and with store clerks. Their planning processes included a wider range of people. For example, one youth's father was not involved in the IEP and the youth asked a school security guard, with whom he was friends, to attend and participate. The school security guard was pleased to be involved and understood that he was an adult male that the youth considered important to him. "You can never close the door to relationships... with the family, with the youth or with the community. It takes a lot of time, "said the community connector.

\section{What are implications for youth development professionals working as community connectors for youth with special health care needs and/or disabilities?}

One of the key elements of this project was the importance of a well-placed, dedicated community connector. Having ties to a local community can have great advantages for those involved in youth development outreach. Effective community connectors in this project live in the same city, community or neighborhood as the youth and care deeply about community life and young people. Youth development professionals in the extension system understand the importance of encouraging ties to family and community (belonging) to help make positive things happen for youth (Kress, 2005).

Being a community connector is not a full-time, paid position. Community connectors were funded with small mini-grants that typically reimbursed them for a few hours a week of their time and for their travel. For example, one community connector was paid $\$ 1500$ for her involvement in the project and had a full-time career separate from the project. Another community connector saw this work as a natural extension of her professional and personal work with youth. She was not paid a stipend, nor did she request one.

Regardless of whether community connectors were paid a stipend for their part-time work with youth in transition, the characteristics of successful community connectors that helped youth achieve transition and inclusion-oriented outcomes with the person-centered, asset-based community development approach are described below. Successful community connectors: 
- demonstrate a welcoming attitude;

- think creatively about who is willing to refine and change ideas and strategies over time and know many people and places in the community;

- follow through on commitments to youth, family and community contacts;

- understand how to decrease formal supports as new connections emerge, know how to step back when youth and community members are working together successfully;

- relate to people from all walks of life, with all types of values, even if they are not his or her own;

- $\quad$ have the ability to be comfortable in people's homes, workplaces, community centers, churches, schools, wherever they want to meet;

- show comfort with asking questions;

- take a genuine interest in people's lives;

- display patience with the process of self- and community discovery;

- have willingness to take risks and ask favors;

- exhibit the creative ability to see connections between people's interests and activities already occurring in the community;

- hold an abiding interest in helping people and communities flourish;

- demonstrate stamina and perseverance; and

- enjoy bringing people together and acting as "host".

\section{Recommendations}

Youth development professionals have enormous potential for serving as community connectors for youth with special health care needs and/or disabilities in youth transition to adulthood as many understand asset-based approaches as well as the importance of youth passion in connecting youth with community resources, opportunities and partners. For those interested in assisting youth with special health care needs and/or disabilities in transition to adulthood, learning about a youth's interests and assets is a good place to begin. Helping youth achieve transition- and inclusion-oriented outcomes can broaden the experiences of the youth and all involved in the on-going process of transition.

\section{References}

Bent, N., Tennant, A., Swift, T., Posnett, J., Scuffham, P. \& Chamberlain, M.A. (2002). Team approach versus ad hoc health services for young people with physical disabilities: a retrospective cohort study. The Lancet, 360, 1280-1286.

Betz, C. (2004). Transition of Adolescents with Special Health Care Needs: Review and Analysis of the Literature. Issues in Comprehensive Pediatric Nursing, 27, 179-241.

Blum, R., White, P. \& Gallay, L. (2005). Moving Into Adulthood for Youth with Disabilities and Serious Health Concerns. In Network on Transitions to Adulthood Policy Brief. Philadelphia, PA: MacArthur Foundation Research Network on Transitions to Adulthood and Public Policy.

Hanley-Maxwell, C. (1999). Transition from school to adult life. In D. J. Reschly, W.D. Tilly, \& J.P. Grimes (Eds.), Special education in transition: Functional and noncategorical programming (pp. 139-167). Longmont, CA: Sopris West. 
Hogan, D. \& Astone, N. (1986). The Transition to Adulthood. Annual Review of Sociology, 12: 109-130.

Kress, C. (2005). Transforming the Lives of Youth: The Essential Elements of Youth Development, National Afterschool Association keynote.

Kretzmann, J. \& McKnight, J., (1993). Building Communities From The Inside Out: A path toward finding and mobilizing a community's assets. Evanston, IL: Institute for Policy Research.

McKnight, J.L. \& Pandack, C.A. (1996). New Community Tools for Improving Child Health: A Pediatrician's Guide to Local Associations. Evanston, IL: Institute for Policy Research.

McPherson, M., Arango, P., Fox, H., Lauver, C., McManus, M., Newacheck, P., Perrin, J., Shonkoff, J., and Strickland, B. (1998). A new definition of children with special health care needs. Pediatrics,102(1):137-140.

O'Connell, M. (1990). Community Building in Logan Square: How a Community Grew Stronger with the Contributions of People with Disabilities. Evanston, IL: Institute for Policy Research.

Russell, M., Reinbold, J. \& Maltby, H. (1996). Transferring to Adult Health Care: Experiences of Adolescents with Cystic Fibrosis. Journal of Pediatric Nursing 11, 262-268.

Swedeen, B. (2003). Stories of Transition to the Adult World, publication of Wisconsin Healthy \& Ready to Work http://www.waisman.wisc.edu/cedd/WRC/Txt/transitionstories.html

White, P.H. \& Gallay, L. (2005). Primer on Health Care Access for Young Adults with Disabilities. In Network on Transitions to Adulthood Policy Brief. Philadelphia, PA: MacArthur Foundation Research Network on Transitions to Adulthood and Public Policy.

U.S. Department of Health and Human Services, Health Resources and Services Administration, Maternal and Child Health Bureau. (2004). The National Survey of Children with Special Health Care Needs Chartbook 2001. Rockville, Maryland: U.S. Department of Health and Human Services.

\section{Acknowledgement:}

The Waisman Center received its Healthy \& Ready to Work funding directly from the United States Department of Health and Human Services, Health Resources and Services Administration, Maternal and Child Health Bureau, Division for Children with Special Health Care Needs (Grant \#H01MC00044).

We would like to acknowledge and thank the following people for their work with this demonstration project: Dan Bier, Project Director Wisconsin Healthy \& Ready to Work Project; Sharon Fleischfresser, Medical Director for the Title V Children with Special Health Care Needs Program in the Bureau of Community Health Promotion at the Wisconsin Division of Public Health; Patti Hackett, Co-director and Project Lead for the Healthy \& Ready to Work National Center and Monique Fountain, Maternal and Child Health Bureau Project Officer. We would like to thank the following people for the ways in which their suggestions improved earlier versions of this manuscript: Greg Hutchins, Matt Calvert, Nancy Franz, Mary Michaud, John Klatt, Mary Ellen Bell, Mary Thiry, Ellen Taylor-Powell and Kathy Blomquist. 


\section{Appendix}

\section{Resource: Planning for the Future}

These are notes from a future planning session for:

Planning Participants Included:

School:

Date:

This planning tool was developed for the Healthy and Ready To Work (HRTW) grant of the Waisman Center. Material was borrowed from Pathfinders Personal Futures Planning by Beth Mount and Connie Lyle O'Brien, and material developed at the Marsha Forest Centre in Toronto by Marsha Forest, Jack Pearpoint and John O'Brien. 


\section{Dreaming, or "The North Star"}

Use this space to create a vision for the future. What kind of life does the person want, and what kind of life do those around the person want for him/her? Try to articulate an ideal vision for home, work, relationships, activities, and services such as direct support, health care, etc. Use this time to reveal what is most important to this person, his/her family and those closest to them. Timelines and limitations are not important during this part of the discussion.

\section{Who Is This Person?}

Make a list of 5-10 statements that best describe this person from a capacity view. What are his/her attributes and abilities that become gifts when they are shared with others? 


\section{Staying Strong:}

Things To Do and Things To Avoid

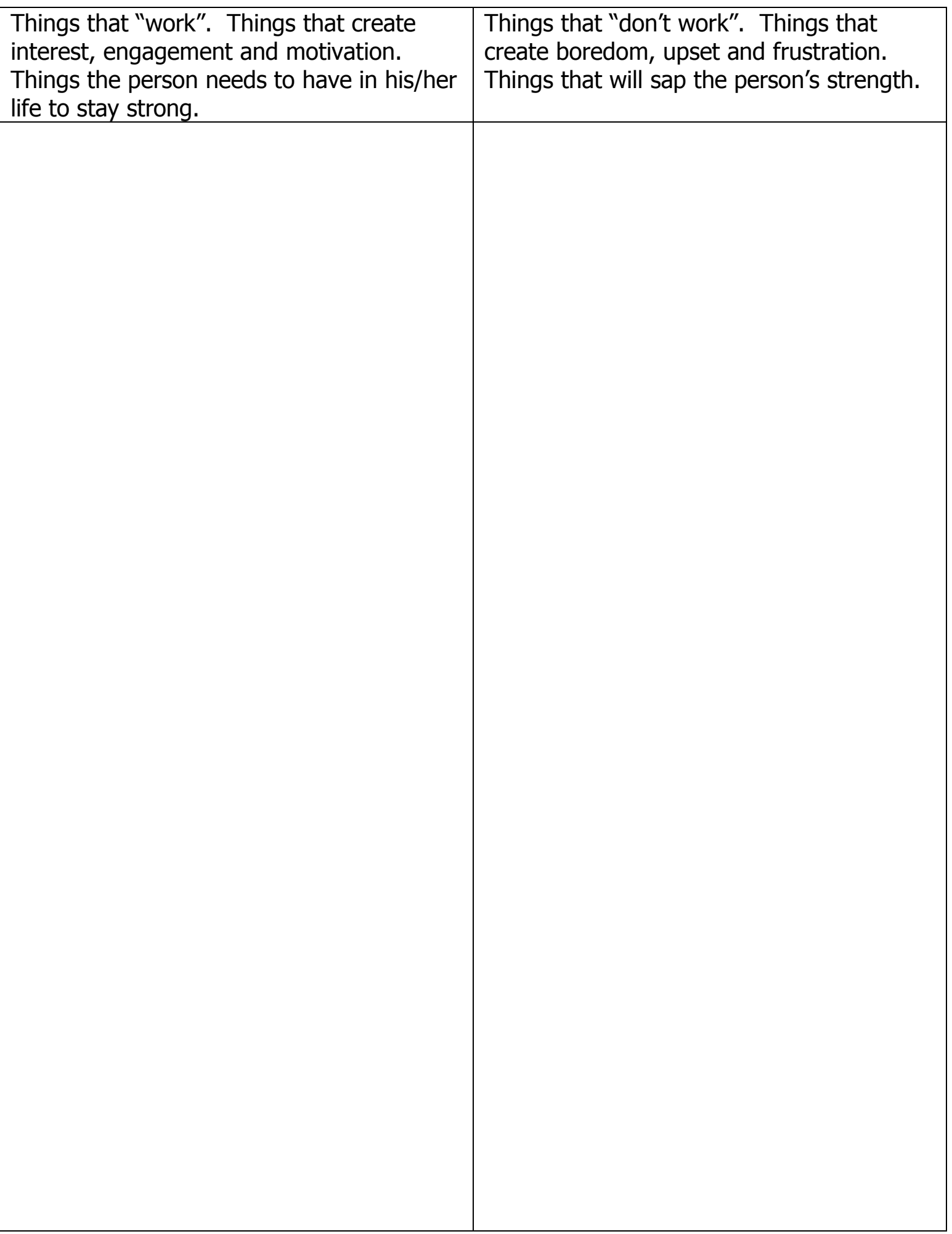




\section{Connections}

\section{A. People:}

Make a diagram, with the person in the center, of the people in the person's life, including people who may be interested in planning together over time. Note the nature of the connection to the person, e.g. family, friends, paid support, long term or short term, etc.

\section{B. Places:}

Make a diagram of the places in the community where the person spends his/her time. This will include home, school and other connections the person may have. Note the places the person most enjoys and those where the person has the least success. Note which places the person may want to increase his/her participation and involvement. 


\section{Goals: The First Year After High School}

Think back to the categories you explored in the first, or dream, step. Project yourselves to one year after leaving High School and list where in each of those categories the person should be. There may be more activity in some areas than others. At what state will the person be regarding work, home, relationships, activities, personal supports, adult health care, etc. Be specific. Also, make sure not only that each goal is reasonable and achievable, but that the totality of the goals are possible to achieve and not overwhelming. 


\section{Building Community Connections}

Think about the goals for after High School, the dreams for the future, the person's actual and potential gifts, and to whom and where he/she is connected, And fill in the chart below to give the group some ideas about where the person could create and/or strengthen existing community connections.

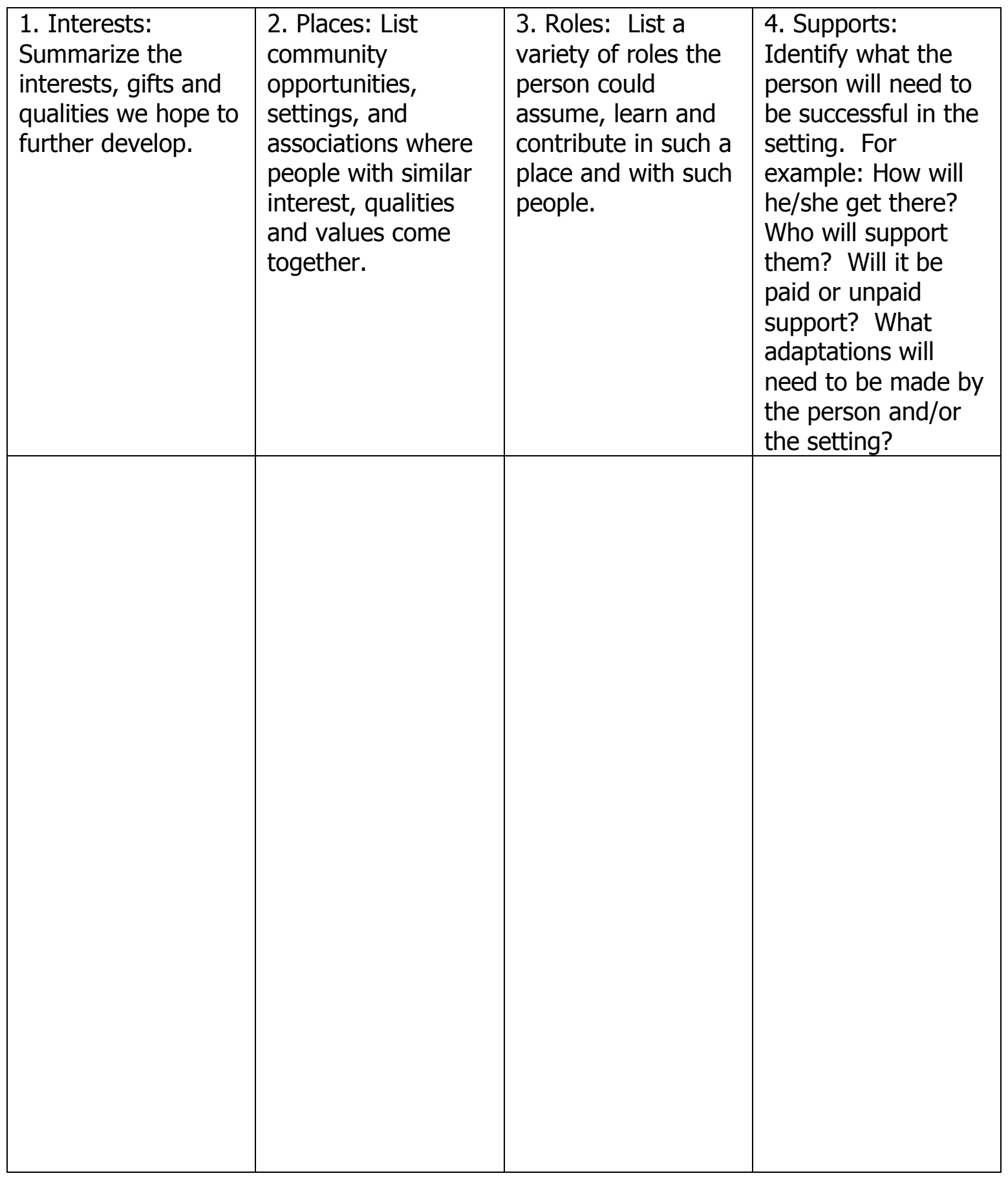


6. Building Community Connections (con.)

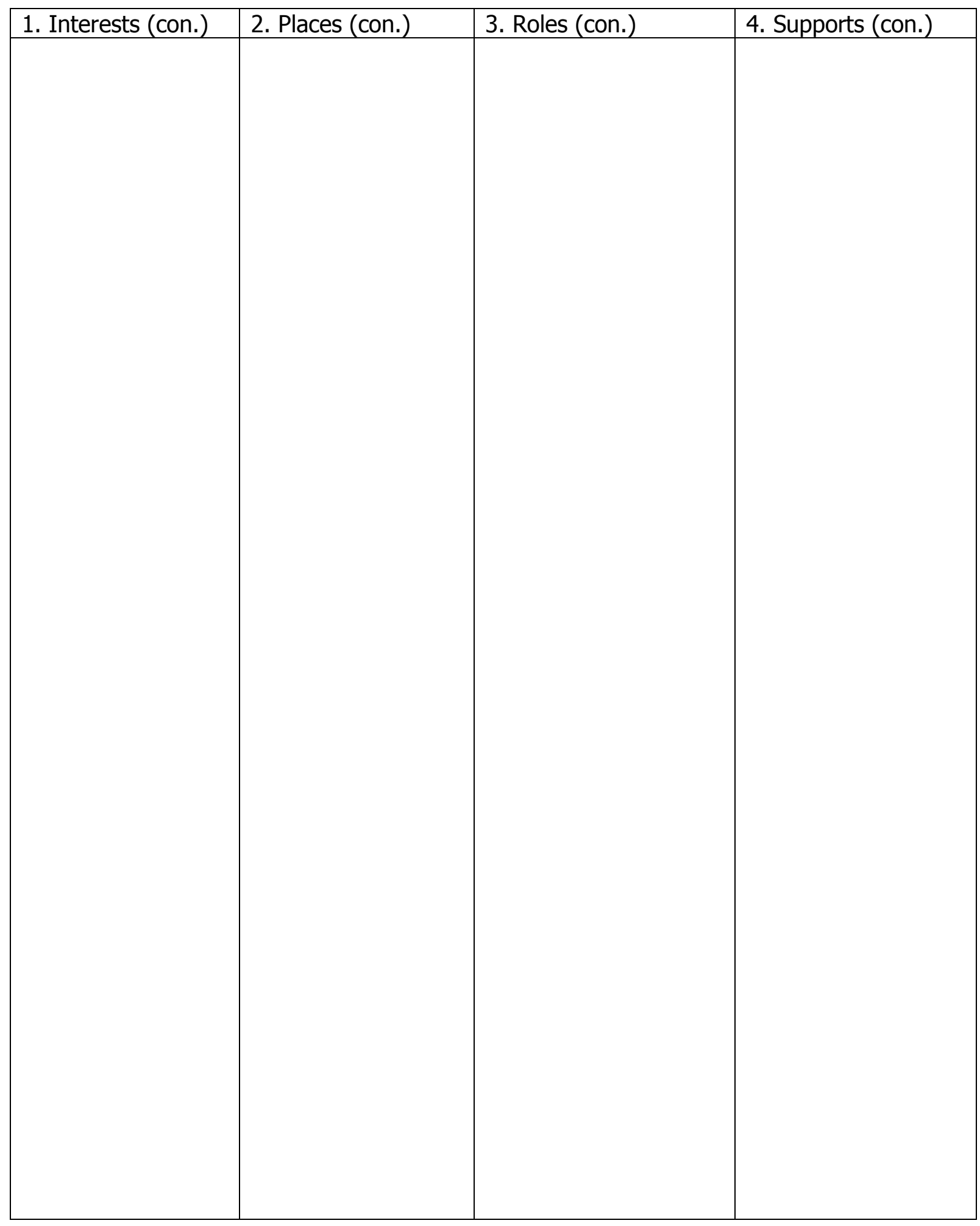




\section{The Next Few Months}

Pick a date two to four months from now. Then make a list of where the person needs to be on their way to the goals you developed for the first year after High School. Some abilities and connections may be fully developed, others you may not have even started working on, and most will be somewhat in the middle. In developing these interim goals, you once again want to make sure they're possible to achieve in the timeframe, and not overwhelming in their totality.

\section{Getting Started}

Now's the time to develop a first step for the goals you've listed above. Remember, "A journey of a thousand miles begins with a single step." In developing these first steps, answer these questions:

- What specifically, is the action to be completed?

- Which people will do it?

- Who will coach and check in with those people at the completion date?

- When will the group next meet to check in on progress and develop the next steps?

(C) Copyright of Journal of Youth Development Bridging Research and Practice. Content may not be copied or emailed to multiple sites or posted to a listserv without copyright holder's express written permission. However, users may print, download or email articles for individual use. 